\title{
AS POSSIBILIDADES DO DESENVOLVIMENTO ECONÔMICO NUM PAÍS DE CAPITALISMO DEPENDENTE: $O$ CASO DO BRASIL
}

\author{
Wolney Roberto Carvalho'
}

\section{Resumo}

A partir de uma breve consideração sobre as origens do desenvolvimento econômico no seio das Ciências Econômicas, elabora-se um estudo sobre a inserção do Brasil ainda colônia no capitalismo, e busca-se inferir e responder sobre o status do desenvolvimento econômico brasileiro, suas limitações e possibilidades a partir da formação do Estado nacional e da produção e reprodução especificamente capitalista implantada no país no século XX.

Palavras-chave: Desenvolvimento Econômico. Capitalismo Dependente.

Classificação JEL: O54, P16.

\section{INTRODUÇÃO}

O estudo do desenvolvimento econômico deverá estar pautado a partir de uma teoria do desenvolvimento econômico, a qual por sua vez, estará fundamentada sempre sobre análises de como os homens se relacionam na produção, distribuição e acumulação dos bens produzidos.

Esse é o debate que se estabelece no seio da ciência econômica atual, mas que tem suas origens nos séculos XVIII e XIX.

Em 1776, o filósofo inglês Adam Smith investiga a causa e as origens da riqueza das nações partindo da análise do processo de produção de mercadorias.

Economista, Mestre em Economia e Doutor em Sociologia Política pela UFSC. Professor Adjunto da Universidade Federal da Integração Latino-americana. E-mail:wolneyc@hotmail.com 
Num primeiro momento, Smith - diferentemente dos fisiocratas que acreditavam que a riqueza se originava apenas do trabalho agrícola - percebe que o trabalho é a fonte de toda a riqueza, aparecendo não apenas no espaço agrícola, mas em outras esferas sócio-econômicas.

De acordo com Nunes,

\begin{abstract}
Adam Smith foi além das várias formas de trabalho concreto que se encontram na vida real, e elaborou uma nova categoria, a de trabalho abstracto, a qual - ele próprio reconhece -, “embora possa tornar-se suficientemente inteligível, não é de modo algum tão natural e óbvia." Esta foi uma novidade teórica particularmente importante. (2007, p. 17-18)
\end{abstract}

Ao filosofar sobre o movimento dos homens no renascimento e suas relações com a riqueza, compreende que a propensão natural dos homens para as trocas nos mais diversos mercados induz à divisão do trabalho no processo de produção das mercadorias e isto, resultando num aumento da destreza do trabalhador, na economia de tempo e na utilização gradativa de máquinas, implicaria por sua vez num aumento da produtividade social do trabalho.

Desse modo, o ato da criação da riqueza se dará com o trabalho produtivo realizado pelo trabalhador junto às matérias-primas, propriedade do empresário industrioso. Este trabalhador criará, assim, através do trabalho comandado, um valor que corresponde ao seu salário - trabalho necessário - bem como a renda da terra e o lucro - parte do qual poderá se transformar em juros.

Smith também deixará claro que o empresário industrioso visará sempre o lucro, ou seja, essa será a razão de sua existência, pois corresponde à recompensa pelo risco ao qual se sujeita por aplicar seu capital no processo de produção de mercadorias. Note-se que é relevante perceber que a origem do capital do empresário, advém de sua poupança.

Para Nunes,

Na construção smithiana, a acumulação do capital surge como a pedra angular da sua teoria do desenvolvimento econômico, uma vez que da dimensão da acumulação do capital depende não só o número de trabalhadores que podem ser utilizados na produção (este número só pode aumentar se aumentarem os "fundos necessários à sua manutenção", i.e, se aumentar o capital), mas também o nível de produtividade dos trabalhadores produtivos:(2007, p.25). 
Contudo, será a partir de David Ricardo, discípulo de Smith, que a análise do desenvolvimento econômico toma fôlego, pois este, defendendo ideologicamente a classe industrial inglesa do início do século XIX frente aos proprietários de terras, juntamente com Malthus, tenta explicar como se dava a distribuição da renda total a partir das variações dos preços, no caso, o preço do salário.

Seu raciocínio partia de dois postulados: "o princípio da população", formulado por Malthus, e a "lei dos rendimentos decrescentes", que se supunha prevalecer na agricultura. Esses dois postulados possuíam um claro fundamento ideológico, apontando o primeiro para a teoria dos salários e o segundo para a teoria da renda do solo. Ricardo que, consciente ou inconscientemente desempenhou o papel ideológico da classe industrial inglesa, argumentava que a renda da terra tendia a crescer toda vez que se utilizavam terras de inferior qualidade. Por outro lado apoiando-se no "princípio de Malthus", dizia que a população tendia a crescer sempre que o salário do operário superava o nível de subsistência. O ritmo de acumulação teria de ser grande e a renda da terra baixa. Salários altos significavam, entretanto, crescimento rápido da população e utilização de terra de inferior qualidade. (FURTADO, 1979, p.9)

Daí que surge a teoria das vantagens comparativas, tão difundida nos dias de hoje. Tentando resolver a problemática do antagonismo entre lucros (altos/baixos) e salários (altos/baixos), que em última instância estivera sempre associado aos meios de subsistência consumidos pelo trabalhador, Ricardo propusera aos países que se especializassem na produção daquelas mercadorias que estivessem mais aptos para produzir e comercializar.

Note-se como Ricardo tivera em mente resolver dois problemas ao mesmo tempo. O primeiro se referia às possibilidades de aumento da oferta de alimentos através da importação, o que refletiria numa queda dos preços dos meios de subsistência consumidos pelos trabalhadores, e também dos salários, reduzindo assim as pressões sobre os lucros. Aumentar-se-ia a acumulação de capital na esfera produtiva, e seria eliminada a transferência de parte dos lucros do setor produtivo que se direcionavam para os proprietários de terra quando do aumento na demanda por alimentos e da necessidade de utilização de terras de qualidade inferiores. 
O segundo, diz respeito à necessidade da divisão internacional do trabalho para a acumulação de capital. Assim, a Inglaterra se especializaria na produção de produtos manufaturados e posteriormente elaborados na grande indústria, e os demais países - em especial as colônias - ficariam responsáveis pela produção de especiarias, produtos agrícolas em geral.

Por último, vale destacar que Ricardo também propusera a utilização de novas tecnologias que poderiam ser utilizadas para substituir os trabalhadores e evitar a elevação dos salários e a queda nos lucros.

Portanto, percebe-se que a discussão do desenvolvimento econômico em Ricardo está centrada na distribuição do produto criado pelo trabalhador (que para ele aparece na forma de salários, renda da terra, juros e lucros) e como esta interfere na dinâmica da acumulação capitalista. Eis as origens da análise contemporânea do desenvolvimento econômico.

Durante todo o século XX, o mainstream da ciência econômica se assentou na busca pelo crescimento do Produto Interno Bruto para posteriormente realizar a divisão deste produto/renda. $\mathrm{O}$ debate na mídia e nos meios acadêmicos do mundo inteiro girou sempre em torno do crescimento econômico e da renda-per capita. É dentro desse cenário que na América Latina e no Brasil do final dos anos 1940 e início dos anos 1950, o debate sobre o desenvolvimento econômico se estabelece.

A partir da CEPAL, organismo composto na sua grande maioria por economistas e sociólogos latino-americanos, que se constata e se discute as especificidades da estrutura econômica, social e política da América Latina.

Acreditando que as teorias do desenvolvimento econômico propagadas tanto pelos Estados Unidos - keynesianismo - quanto pela Rússia - proposta socialista - não poderiam ser aplicadas na sua essência, os teóricos cepalinos propõem uma nova teoria para o desenvolvimento econômico latino-americano: era um misto das teorias, ricardiana, schumpeteriana, keynesiana e marxista do desenvolvimento econômico.

Esta nova teoria teria como missão acabar com a heterogeneidade estrutural do país através da modernização do campo e das cidades; eliminar a deterioração dos termos de intercâmbio através da internalização e substituições de importações bem como da modernização tecnológica das atividades industriais; proteger a indústria nascente; aumentar a participação do Estado nos setores estratégicos da economia como na criação de infra-estrutura, na indústria de bens de produção mais onerosas para o capital, assim como 
criar mecanismos de cessão de crédito; promover uma reforma agrária e aumentar a oferta de alimentos no mercado interno, permitindo com isso o barateamento do custo de reprodução da força de trabalho

Entretanto, apesar das propostas da CEPAL, parte das quais foram aplicadas, a problemática do desenvolvimento econômico e a condição da América Latina como o espaço do capitalismo dependente, continuaram em vigência.

Na realidade, a discussão e implantação do modelo de desenvolvimento econômico que prevaleceu no Brasil nas décadas que se seguiram e até os dias de hoje, não se distinguiu essencialmente da raiz ricardiana. Os debates que giraram em torno de novas teorias do desenvolvimento, como a da proposta keynesiana, a monetarista, e nos dias de hoje, a dos chamados novos clássicos e a dos novos-keynesianos - análises essencialmente abstratas e a-históricas-, continuam amparadas na aceitação da lei da oferta e da demanda e na aceitação de que o desenvolvimento econômico se expressa pela via do crescimento econômico e pela distribuição de renda.

Com base nisso é que se pretende demonstrar como a análise, a interpretação e a verificação das possibilidades do desenvolvimento econômico brasileiro devem ser buscadas na história da inserção da Colônia-brasilis no capitalismo do século XVI, bem como da gênese e do desenvolvimento das relações de produção especificamente capitalistas no Brasil a partir de sua independência.

\section{DA INSERÇÃO DO BRASIL COLÔNIA NO CIRCUITO DO CAPITALISMO EUROPEU}

Como resultado do dinamismo e da acumulação do capital mercantil europeu, as grandes navegações tornam possível a descoberta de novas regiões e novos povos, de modo que se aprimoram e se aprofundam o comércio de mercadorias, bem como serão descobertas novas fontes que incrementarão a acumulação primitiva européia, que por sua vez tornarão possível o advento do Modo de Produção Capitalista no espaço europeu nos princípios do século XVI.

Nesse sentido, é importante observar que se o capital mercantil ou comercial - que aparece consolidado na figura do mercador já na baixa 
Idade Média - está assentado na comercialização de mercadorias produzidas por mestres artesãos ou proprietários privados dos meios de produção e do produto do seu trabalho, o Modo de Produção Capitalista, por sua vez, se assenta sob ciclo de reprodução do capital industrial - que subordina o capital comercial e o torna uma forma funcional do capital - e traz em seu seio, a separação entre os proprietários dos meios de produção e os detentores da força-de-trabalho - homens livres.

Portanto, a América Latina fora inserida no mercado capitalista mundial em 1492 e desde o início do movimento histórico de colonização, coincidem as etapas finais da crise do mundo medieval europeu e a sua revitalização nas colônias, manifestando através do regime estamental, assentado sobre a grande plantação, o trabalho escravo e a expropriação colonial.

No Brasil, segundo Ávila (2006), a colonização se inicia em 1500. Num primeiro momento, os Portugueses - aliciando e manipulando os índios buscaram descobrir fontes de metais preciosos, mas sem sucesso, partiram logo em seguida para a exportação de pau-brasil, do qual se extraíra a tintura que fora amplamente utilizada no tingimento de tecidos comercializados em especial na Europa durante os primeiros 50 anos após o descobrimento.

Com a rápida escassez da madeira, entre 1550 e 1650 introduziu-se no Brasil o cultivo da cana-de-açúcar, técnica já dominada pelos portugueses açorianos.

Com o cultivo da cana, surgiram os grandes engenhos e a necessidade de uma mão-de-obra disciplinada para o trabalho cotidiano. O nativo, que estava habituado à outra lógica para adquirir a materialidade necessária à sua subsistência, não consegue se adaptar aos trabalhos forçados requeridos pelos senhores de engenho, e faz-se a partir desse momento a importação e ampla utilização da mão-de-obra escrava - originária em grande medida da África - nas plantações e cultivo dos produtos coloniais em geral.

Assim, se a comercialização dos produtos coloniais se realizara no circuito do capital comercial, o mesmo se dera com a comercialização dos escravos, pois

...a escravidão moderna é, em sua essência, uma "escravidão mercantil": o escravo não só constitui uma mercadoria; é a principal mercadoria de uma vasta rede de negócios (que vai da captura e do tráfico ao mercado de escravos e à forma de 
trabalho), a qual conta, durante muito tempo, como um dos nervos ou mola mestra da acumulação do capital mercantil. (FERNANDES, 2004, p.367)

Assim sendo, até meados do século XVII o açúcar tem um grande valor no mercado europeu, propiciando para a Coroa Portuguesa uma fonte de acumulação primitiva que se esvaíra com a perda do monopólio para os holandeses na segunda metade do século.

De acordo com Fernandes (2004), percebe-se desde já que toda orientação no que diz respeito à exploração econômica das colônias européias, traz em si a especialização na produção de gêneros coloniais observados pela metrópole sempre em sintonia com o mercado capitalista em expansão, mas mesmo assim, o grosso do excedente econômico oriundo da produção colonial de base escravista, não ficara nas mãos da Coroa e nem dos Senhores apesar de proprietários dos escravos, pelo menos até a primeira metade do século XIX. Sob a égide do capital comercial ou mercantil, a principal parte do excedente econômico ficara nas mãos dos negociantes metropolitanos e dos centros hegemônicos.

Com o fim do monopólio da produção de açúcar e para previnir-se de outras invasões européias, - de acordo com Ávila (2006) - a Coroa passa a adotar a estratégia de ocupação do interior do território brasileiro, tendo à frente o capitão do mato Fernão Dias - grande caçador e escravizador de índios - que já no século XVII conduzindo as chamadas bandeiras, adentrara a região serrana de Minas Gerais e descobrira as primeiras esmeraldas. Assim, entre a segunda metade do século XVII e o final do século XVIII estabeleceu-se no Brasil o ciclo da mineração, do qual a Coroa portuguesa se beneficiara muito. Contudo, apesar da prosperidade na exploração dos metais em terras da colônia, isso não fora o suficiente para solucionar os problemas econômicos em Portugal, tanto que em 1808 a família Real se transfere juntamente com seus séquitos para o Brasil.

Note-se que - apesar da mineração e seus produtos terem tido a primazia ao longo do período considerado, fato que caracteriza o ciclo acima descrito -, em conformidade com Ávila (2006), a economia colonial não cessou e em diferentes regiões foram cultivadas diversas riquezas naturais, como o fumo na Bahia, o algodão no Maranhão e no Pará, a pecuária no norte, litoral e posteriormente no interior. 
Entretanto, com a queda dos preços no mercado internacional do açúcar e do algodão - dificultando as finanças da colônia e da Coroa - que eram os principais produtos de exportação, estabelece-se um novo ciclo econômico agora centrado no cultivo do café nos Estados de Rio e São Paulo. Entre 1820 a 1930 surgiram no país as grandes fazendas de plantação do café, tendo também na base da produção a mão-de-obra escrava.

Assim, desde os primeiros 50 anos após a descoberta do Brasil até os primeiros 20 anos do século XIX, a dependência da colônia em relação à metrópole se dá no âmbito econômico, jurídico e político, e a vinculação com o mercado capitalista em ascenção se dá através do comércio dos produtos coloniais - inicialmente do pau-brasil, passando pela cana-de-açúcar, os metais, o algodão, o café e outros produtos de menor relevância na pauta de exportações - bem como da comercialização da mão-de-obra escrava, base da produção colonial.

Observa-se, todavia, que até esse momento, o Senhor que é proprietário de escravos - pois imobiliza boa parte do seu capital na compra destes - e coordena a produção dos produtos coloniais, é duplamente extorquido. Por um lado e em menor grau pela Coroa através de tributação, associação e concessões e, por outro lado, pelos negociantes estrangeiros que se apropriavam da maior parte do excedente.

\begin{abstract}
Algumas partes e certas fases do negócio se desenrolavam no cenário comercial e financeiro da metrópole; porém, a parte substancial encontrava-se nos núcleos estrangeiros, que manipulavam à distância e indiretamente os nervos das economias coloniais e de sua articulação às economias e ao mercado mundial: a mercantilização dos "produtos coloniais" e todas as operações ou resultados financeiros de vulto iam ter nas suas mãos. Portanto, como o Senhor, a Coroa e a metrópole não ficavam com a "parte do leão". O capital mercantil tecia as redes que não deixavam escapar os peixes grandes e o seu apetite era insaciável.(FERNANDES, 2004, p.374).
\end{abstract}

Dado o exposto acima, constata-se que, a maior parte do excedente econômico produzido pela colônia se direcionava para o capital mercantil europeu - Metrópole, Holanda e Inglaterra principalmente - que num primeiro momento serve de base para a constituição do capital industrial europeu e posteriormente se transforma em forma funcional deste capital. 
Enquanto isso, não há a menor possibilidade de acumulação primitiva, e muito menos de uma acumulação do capital comercial na colônia que possibilitasse o advento de uma base produtiva essencialmente capitalista, ou seja, da ocorrência de uma revolução econômica burguesa como ocorrera na Europa do século XVII.

\section{A ACUMULAÇÃO DO CAPITAL COMERCIAL BRASILEIRO E A GÊNESE DA PRODUÇÃO E REPRODUÇÃO ESPECIFICA- MENTE CAPITALISTA: EM BUSCA DO DESENVOLVIMENTO ECONÔMICO}

Tanto a acumulação primitiva como a acumulação do capital comercial em solo brasileiro somente serão possíveis após a constituição do Estadonação nos anos 20 do século XIX.

É partir desse período que os Senhores se livram do peso pecuniário que representara a Coroa, e a partir de então poderão dispor livremente do produto do trabalho escravo, que continua sendo a base do ciclo do café.

Faz-se relevante perceber que - de acordo com Fernandes (2004a) com a abertura dos portos, o vice-reinado e a independência, os ganhos do comércio de escravos (tráfico) vão sendo retidos no país e isto contribui decisivamente para a acumulação do capital mercantil brasileiro. É o capital mercantil se fortalecendo.

Também com o início do ciclo cafeicultor nos Estados do Rio e São Paulo, estes Senhores passam a organizar os negócios comerciais e financeiros a partir das cidades, que pouco a pouco se urbanizam e concentram os negócios de exportação tanto dos produtos agrícolas como de escravos, bem como os negócios financeiros. É o capital mercantil atuando.

Contudo, de acordo com Fernandes (2004a), será a internalização de complexas funções comerciais e financeiras nos centros urbanos que possibilitará ao capital mercantil acumulado pelos Senhores - aliado ao capital mercantil do exterior - realizar o seu potencial revolucionário e transformar parte da oligarquia tradicional em oligarquia moderna. É o capital mercantil possibilitando o advento da revolução burguesa no Brasil, uma revolução protagonizada pelos Senhores e pela elite imigrante.

Mas o início da revolução burguesa no Brasil se processará a partir da oligarquia moderna que, se por um lado tem vículos com a oligarquia tra- 
dicional (agrária), por outro conseguirá se renovar nas estruturas do poder político, social e principalmente econômico no centros urbanos em ascenção, orientando os demais setores da classe dominante - inclusive a alta e média classes urbanas - e reprimindo os trabalhadores quando necessário. Conforme Fernandes (2004b), a revolução se processará a partir de dentro e de cima para baixo. Uma revolução dentro da ordem.

As elites apelaram, assim, para o controle autocrático, ainda que isto ferisse a livre-empresa, a livre iniciativa, o Estado representativo.

No que diz respeito especificamente ao plano econômico, o qual possibilitou as bases materiais para a acumulação do capital comercial e a posterior implantação do capital industrial, a elite preservou as fontes do capital comercial que se baseavam nos negócios de exportação e importação e ao mesmo tempo dinamizou com este a implantação do capital industrial nos principais centros urbanos.

No entanto, é importante perceber que logo que fora extinto o sistema colonial e surge o Estado nacional brasileiro, a elite ao preservar as fontes do capital comercial em torno do comércio exterior de produtos coloniais - e também de escravos -, manteve a antiga estrutura econômica em função da demanda do mercado mundial e da forte influência dos importadores europeus que auferiam grandes lucros. Se no plano político ocorrera a independência do país, no plano econômico estabeleceram-se as bases do neocolonialismo.

Apesar de a oligarquia tradicional se modernizar pouco a pouco e conservar as bases de acumulação do capital comercial, não consegue reter todo o excendente econômico, pois uma parcela importante dos negócios de importação-exportação ficara sob o controle de agentes treinados nos países centrais que abocanhavam grandes fortunas.

Também, se a oligarquia modernizada atuará para além da agricultura, ou seja, nos grandes centros urbanos em torno dos negócios comerciais, financeiros e de serviços, isto não impedirá que parte destes negócios viessem a ficar nas mãos dos estrangeiros, os quais remetiam para o exterior parcela considerável do excedente econômico dessas atividades.

Isso fez com que desde o surgimento do Estado-nação brasileiro, se implantantasse no país uma economia nacional dependente, pois, 
este é absorvido, de início, pela inclusão no mercado mundial e através do processo de modernização, que converte a economia nacional em núcleo dependente e satélite, inclusive na vigência das formas econômicas imperantes na metrópole econômica (ou "imperial"). Por fim, cumpre observar os aspectos peculiares da situação econômica em que se operou o tipo mencionado de acumulação originária. O controle externo dos "negócios de exportação e importação", bem como da construção de uma rede moderna de comércio, bancos e outros serviços, redundava num processo crônico de capitalização para fora, ou seja, de exportação do excedente econômico como consequência da integração dependente na economia capitalista mundial. (FERNANDES, 1968, p.46)

Portanto, com base no acima exposto, constata-se apesar de a oligarquia moderna - sempre apoiada pelos estratos da classe média urbana em ascensão - manter as fontes de acumulação do capital comercial após a independência do país, isso não será suficiente para criação de um Estadonação capitalista independente, pois a concretização da revolução burguesa no plano econômico internamente estivera alicerçada sobre uma acumulação de capital primitivo e comercial insuficiente, de modo que apenas se efetivará com o entrelaçamento dos interesses econômicos dessa oligarquia moderna com o capital externo.

A implantação no país das bases da produção e reprodução especificamente capitalista, sob o comando do capital industrial - representado por Marx como todo o capital e que subsume o capital comercial e usurário, e os transformam em formas funcionais - terá sua gênese na associação do capital comercial brasileiro - acumulado no período neocolonial - com o capital oriundo dos centros hegemônicos.

Para Fernandes,

No conjunto, pois, delineia-se toda uma situação específica dos povos de capitalismo dependente. A acumulação originária de capital associou-se, em termos de interesses comuns defendidos conscientemente, mesmo no nível político, ao fluxo permanente do capital externo, sem nunca disputar com os centros hegemônicos sequer as posições estratégicas de controle do crescimento interno. Sua lógica se inspirava nos interesses e possibilidades do capitalismo dependente. Por 
isso, ela não gerou grandes injustiças, violências econômicas ou dramáticas e pilhagens formidáveis. Também não conduziu a outra coisa senão a um capitalismo débil, heterogêneo e controlado de fora" (MARX, 1968, p.46)

No que diz respeito à produção da riqueza material, a organização do mercado de trabalho - onde se poderia comprar e vender livremente a forçade-trabalho - foi lenta e diferente nas mais diversas regiões. O fato é que houve no início a necessidade de dar continuidade à utilização do trabalho extra-capitalista, principalmente por parte da oligarquia tradicional/agrária que não queria perder os investimentos imobilizados na mercadoria-escravo. Também em alguns setores mais dinâmicos das maiores cidades - em especial Rio e São Paulo - utilizaram-se tecnologias importadas e técnicas avançadas, que quando requeriam a necessidade da compra da força de trabalho, esta deveria ser já especializada e com razoável nível de instrução.

Então, a proletarização significava um benefício, pois abria a possibilidade de inserção na estrutura do sistema, ser assalariado, ter renda e poder consumir mercadorias. Esse fora o sonho do escravo livre, do campesino, do homem pobre das médias e grandes cidades.

Note-se que - segundo Fernandes (2004b) - essa diversidade das formas de exploração do trabalhador - capitalista, semi-capitalista e extra-capitalista - também demonstra que a implantação do capitalismo industrial no Brasil, se estabelece assentada sobre uma estrutura heterogênea da produção, onde coexistem e se articulam os setores arcaicos e os setores modernos, o que prevalece ainda hoje em muitas regiões e é característica sine qua non da implantação da produção capitalista nos países de capitalismo dependente.

Contudo, a burguesia nacionalista acreditava inicialmente que sob os desígnios da ampliação da produção industrial e do mercado interno conseguiria implantar no país um capitalismo competitivo e autônomo. Mas já era tarde, esquecera que para o início da revolução burguesa se associara com capitais vindos do exterior e estes, frente à conjuntura internacional de disputas imperialistas e da Grande Depressão dos anos 30, exigiam aqui no Brasil: proteção, segurança e espaço garantido para se reproduzirem, ameaçando, com isso, inclusive algumas empresas de capital nacional que atuavam nos setores mais importantes. A burguesia também se deparou com pressões operárias crescentes e com a forte atuação estatal na esfera 
econômica que vão dos anos 30 (Estado Novo), passam pelo governo JK e culminam em crise democrática com o governo de João Goulart.

De acordo com Almeida (2005), após a "Revolução de 30", ao mesmo tempo que as organizações sindicais e políticas eram perseguidas e o Estado passa a regulamentar as lutas sindicais através da legislação trabalhista, se incorpora demandas sociais e em boa medida criam-se as bases necessárias para o processo de desenvolvimento do capital industrial (ou seja, o assalariamento e a proletarização se acentuam nos principais centros urbanos do país).

Mas, se o governo Vargas institucionalizara a regulamentação e o contrato de trabalho, aumentando a proletarização nos grandes centros, será no governo JK (1956-1961) que o Estado assume tarefas importantes na consolidação do desenvolvimento do capitalismo dependente e propicia a primeira e grande atuação do capital monopolista que se consolidará no espaço nacional após 1964.

Apoiado por um leque de forças - que ia do Partido Comunista, passando pelo grosso do empresariado nativo e se estendia a representantes da grande burguesia estrangeira - o governo teve grande sucesso na tarefa de consolidar o capitalismo industrial (e dependente) no Brasil, até porque soube aproveitar uma conjuntura de grande expansão de capitais na economia mundial. Lembremos também do apoio da maioria dos grandes proprietários de terra, beneficiados pela política desenvolvimentista e tranqüilizados pela indisposição do governo face à reforma agrária. Foi bem mais que um "espetáculo de crescimento" [o PIB cresceu em média $8 \%$ aa]: a população urbana ultrapassou a rural; o setor de bens de produção deslanchou [construção civil, energia, aço...]; a participação industrial no PIB deixou a agrícola comendo poeira;rasgaram-se estradas pelo Brasil afora [resultado da implantação da indústria automobilística na forma de oligopólios altamente concentrados];fábricas foram construídas a mancheias. Houve até um aumento do salário-mínimo real, claro que por pouco tempo e bem abaixo da taxa de exploração da força de trabalho...A burguesia industrial participou gostosamente deste processo, ao longo do qual ela se metamorfoseou. Grande parte se associou, sob múltiplas formas a capitais estrangeiros. Outra parte, minoritária, cresceu e conseguiu preservar seus nichos no interior de uma economia cada vez mais dominada pelo grande capital (privado ou estatal).(ALMEIDA, 2005, p.14) 
No entanto, a burguesia nativa nunca tivera uma postura progressista e jamais aceitara as manifestações populares. O fim do governo JK em 61 e o início do governo Jânio Quadros é um momento marcado pelo início de novos conflitos sociais, em que as taxas de inflação começam a se elevar e os trabalhadores perdem poder aquisitivo; a gestão do Estado tendo a sua frente João Goulart - com a saída de Jânio - elevam os riscos da aparente democracia burguesa. Nesse momento, a burguesia resgata a sua herança política do final do século XIX e juntamente com o apoio incondicional das forças armadas assume diretamente o controle do Estado.

Promoverá a partir de então, em especial até a primeira metade da década de 70 - período em que se realizou o milagre econômico brasileiro e o PIB cresceu em média 11,5\% aa -, as condições políticas, econômicas e sociais para a consolidação do capitalismo monopolista.

Assim, os germes do capitalismo monopolista, que já se faziam presentes no país no final do século XIX e início do século XX, finalmente tomam forma e manifestam a impossibilidade da concretização de uma revolução burguesa nos moldes preconizados politica e economicamente pelo capitalismo europeu do século XIX, a exemplo da França e Inglaterra. Desmascaram a burguesia nativa - de origem oligárquica - mostrando a sua fragilidade na busca e efetivação de uma proposta nacional-desenvolvimentista com vistas à implantação de um capitalismo autônomo, auto-suficiente.

Dessa maneira,

no momento do impasse, a chave das decisões saiu da esfera do político. A reorganização do Estado, a concentração e a militarização do poder político estatal, bem como a reorientação da política econômica sob a égide do Estado foram a mola-mestra de todo o processo de "recuperação" e de volta à "normalidade". Todavia, nada disso foi posto a serviço de uma transição independente e não ocorreu nenhuma ruptura nas relações de dependência: ao contrário, atrás da crise política (a partir de dentro) havia uma crise econômica (de fora para dentro) e esta se resolveu através do padrão de dominação externa (que é o que significou a passagem do capitalismo competitivo para o capitalismo monopolista: uma nova forma de submissão ao imperialismo) (FERNANDES, 2004b, p.447). 


\section{CONSIDERAÇÕES FINAIS}

Como se viu, o Brasil se insere no mercado capitalista mundial desde a colonização. É incorporado ao ciclo do capital mercantil europeu através da comercialização dos produtos coloniais bem como do comércio de escravos.

O sistema colonial fora assentado na utilização da mão de obra-escrava, mas se o Senhor proprietário dos escravos tivera boa parte do seu capital aplicado nessa mercadoria, a qual utilizava para a elaboração dos produtos coloniais depois de 1550, mesmo assim não ficara com a maior parte do produto excedente. A principal parte desse fora abocanhado pelos agentes da metrópole e do exterior - que ficaram com a maior parte durante todo o período colonial - e pela Coroa portuguesa.

Isso foi decisivo, pois a acumulação substancial do capital comercial pelos senhores, que estava assentado na base da produção escravista, na comercialização dos produtos coloniais e na participação do comércio e tráfico de escravos, apenas se realizara no período que vai da independência do Brasil até as últimas décadas do século XIX. Depois da independência eliminam o ônus pecuniário da metrópole, mas não o fazem totalmente com relação aos agentes comerciais e do tráfico de escravos - na maioria estrangeiros - que continuam a gerenciar parte substancial dos negócios de acordo com as demandas do mercado capitalista mundial. Isso é que caracterizará o período que vai da independência política do país até o final do século XIX, como o período neocolonial.

Portanto, se os Senhores brasileiros acumularam capital comercial nesse período, este não será suficiente para a implantação da produção e reprodução especificamente capitalista. Terão de se associar com os capitais vindos do exterior ou acumulados internamente nas mãos de agentes do capital externo.

Eis, assim, a implantação do capitalismo industrial no Brasil, um capitalismo que desde a sua gênese é dependente. Este se caracteriza pela impossibilidade econômica e política da burguesia brasileira em implantar no país um capitalismo auto-suficiente, como ocorrera na Europa dos séculos XVIII e XIX. Impossibilidade econômica porque a burguesia brasileira emergente, de base oligárquica tradicional e moderna, não foi capaz de controlar os negócios essências após a independência e acumular o capital comercial necessário para implantação de um capitalismo autônomo; impos- 
sibilidade política porque foi incapaz para implantar as bases democráticas e institucionais de forma a garantir desde o início, a liberdade dos homens brasileiros, o sufrágio universal e a livre comercialização da compra e venda da força-de-trabalho, base da produção capitalista.

Nesse sentido, e de acordo com Florestan Fernandes, a burguesia brasileira optou pela revolução "dentro da ordem" e "de cima para baixo", pela manutenção das práticas oligárquicas na política e pelo aburguesamento dependente do exterior no plano econômico.

Assim, das primeiras décadas do século XX até o Estado Novo, as organizações e manifestações operárias foram reprimidas fortemente nos moldes oligárquicos. A proletarização fora lenta, e acima de tudo, significava status social, pois a maioria dos trabalhadores, em especial os do campo estavam inseridos em estruturas extra-capitalistas ou semi-capitalistas.

Será o Estado Novo nos anos 1930 que, através da institucionalização e regulamentação da compra e venda da força-de-trabalho, - com a implantação do salário mínimo e a carteira de trabalho - juntamente com a urbanização e industrialização, contribuirá para o ritmo de proletarização no país.

Então, até a primeira metade dos anos 1960, o país se encontra sob a fase do capitalismo competitivo. A urbanização e a industrialização - privada e estatal - dão-se de forma lenta e gradativa. A heterogeneidade estrutural ainda é muito presente, e há no Brasil regiões muito modernas e outras muito arcaicas.

No entanto, se a fase do capital monopolista será iniciada no governo JK, tendo como grande símbolo a implantação da indústria automobilística, esta se consolidará com o governo militar da burguesia na segunda metade dos anos 1960 e durante os anos 1970.

De acordo com Fernandes, "em nome do 'desenvolvimento econômico acelerado', ampliou-se e aprofundou-se, portanto, a incorporação da economia nacional e das estruturas nacionais de poder à economia capitalista mundial e às estruturas capitalistas internacionais de poder." (FERNANDES, 2004b, p.448).

Finalmente, com base no acima exposto, conclui-se que se existiu no país a preocupação com o desenvolvimento econômico, este sempre estivera voltado para o melhoramento das condições especificamente capitalistas, para a acumulação de capital. 
Apesar de ter sido este o objetivo da burguesia brasileira, esta ao não conseguir implantar no país um capitalismo autônomo, relegou aos produtores da riqueza material condições de exploração ainda mais drásticas que as ocorridas com os trabalhadores dos países centrais.

Também permitiu a influência externa nos assuntos políticos do país, e após o início da fase do capital monopolista, cada vez mais nos assuntos de política social e econômica.

Assim, no alvorecer do século XXI, resta-nos indagar: 1) se ainda é possível o desenvolvimento econômico no Brasil se assentar sob as bases do desenvolvimento de um capitalismo nacional autônomo; 2) se o desenvolvimento econômico sob a égide do modo de produção capitalista conseguirá garantir os direitos humanos elementares: alimentação, educação, saúde e habitação para os trabalhadores.

\title{
POSSIBILITIES OF ECONOMIC DEVELOPMENT WITHIN DEPENDENT CAPITALISM: THE BRAZILIAN CASE
}

\begin{abstract}
Taking as a starting point some brief considerations on the origins of the idea of economic development in the history of economic science, this paper aims to study the colonial Brazil insertion in the world capitalist system and to define the status of Brazilian economic development, its constraints and its possibilities. The study focuses on the formation of the national state and the specifically capitalistic production and reproduction that took place in the $20^{\text {th }}$ century.
\end{abstract}

Keywords: Brazil, economic development, dependent capitalism

JEL Classification: O54, P16.

\section{BIBLIOGRAFIA}

ÁVILA, C. Do litoral ao interior: os ciclos econômicos e a formação do Brasil. www.cidadeshistoricas.art.br/hac/hist 
ALMEIDA, J. M. A ilusão do neodesenvolvimentismo. Brasil de Fato. 2 de Março. 2005. SP.

NUNES, A. J. A. A filosofia social de Adam Smith. Rev. Pensar. p. 17-35. Ed. Especial. Fortaleza. Abril. 2007. Disponível em: http://www.unifor.br/ notitia/file/1611.pdf

FERNANDES, F. Sociedade de classes e subsdesenvolvimento. Rio de Janeiro. Ed. Zahar. 1968

Zahar. 1974.

Capitalismo dependente e imperialismo. Rio de Janeiro. Ed.

. Sociologia e socialismo. Opinião. 1975.

A concretização da revolução burguesa. In Florestan Fernandes: sociologia crítica e militante. Org. Octávio IanniSão Paulo. Ed. Expressão Popular. 2004.(a)

A sociedade escravista no Brasil. In Florestan Fernandes: sociologia crítica e militante. Org. Octávio Ianni. São Paulo. Ed. Expressão Popular. 2004 (b)

FURTADO, C. Teoria e política do desenvolvimento econômico. São Paulo. Ed. Nacional. 1979. 